\title{
KAJIAN PERENCANAAN STRATEGIS SISTEM INFORMASI PADA BISNIS RITEL BERBASIS METODOLOGI WARD \& PEPPARD: STUDI KASUS PT. GRAMEDIA ASRI MEDIA
}

\author{
Christina Deni Rumiarti ${ }^{1}$, Bagas Ryant Setiawan ${ }^{2}$, I Dewa Made Pranata Wiana ${ }^{3}$ \\ ${ }^{1}$ Program Studi Sistem Informasi, Fakultas Teknologi Informasi, Universitas Kristen Duta Wacana \\ ${ }^{2}$ Line Station Analyst, Station Automation Support, Garuda Indonesia \\ ${ }^{3}$ Departemen Kebijakan Sistem Pembayaran, Bank Indonesia \\ Email: ${ }^{1}$ christina.deni@ staff.ukdw.ac.id, ${ }^{2}$ bagas.ry@gmail.com, ${ }^{3}$ pranatawiana @ gmail.com
}

(Naskah masuk: 13 Juli 2018, diterima untuk diterbitkan: 03 Mei 2019)

\begin{abstract}
Abstrak
Persaingan global menuntut setiap bisnis melakukan inovasi dalam pemanfaatan sistem dan teknologi informasi (SI/TI) untuk meningkatkan nilai tambah. Alur informasi yang tidak berjalan optimal dapat menjadi kendala bagi bisnis. Terkait hal tersebut, permasalahan yang kemudian menjadi isu penting diantaranya adalah potensi kerugian akibat ketidaksesuaian data stok di sistem inventori dengan stok aktual, serta prioritas pengembangan sistem informasi yang belum terencana dengan matang. Permasalahan tersebut mendorong perlu adanya perencanaan yang matang dan terukur untuk mencapai visi-misi perusahaan. Penelitian ini mengambil studi kasus PT. Gramedia Asri Media yang menjadi salah satu bisnis ritel terbesar di Indonesia. Alur metodologi dalam studi ini terdiri dari analisis bisnis eksternal, analisis bisnis internal, analisis SI/TI eksternal, serta analisis SI/TI internal. Metode untuk menganalisis bisnis internal adalah internal value chain, dan Critical Success Factor (CSF), sementara itu analisis PESTLE, five forces, dan eksternal value chain diaplikasikan untuk menganalisis lingkungan bisnis eksternal. Metode yang digunakan untuk menganalisis lingkungan internal SI/TI adalah Portofolio McFarlan, sementara itu studi literatur dan observasi digunakan untuk melakukan analisis lingkungan eksternal SI/TI. Dengan menggunakan metodologi Ward dan Peppard ini, dihasilkan roadmap SI/TI yang selaras dengan kebutuhan bisnis serta dapat dibangun dalam jangka waktu 4 tahun.
\end{abstract}

Kata kunci: perencanaan strategis, metodologi Ward dan Peppard, value chain, portofolio McFarlan

\section{A STUDY OF STRATEGIC PLANNING INFORMATION SYSTEM IN RETAIL BUSSINESS BASED ON WARD \& PEPPARD METHODOLOGY: CASE STUDY PT. GRAMEDIA ASRI}

\begin{abstract}
Global competition requires every business innovates their systems and information technology (IS/IT) to increase their value. The better the information runs, the wider the value increases. Related to that, some problems becoming important matter are potential losses due to the discrepancy of stock data in the inventory system with actual stock, and the priority of information systems development that have not been well planned as well. This situation encourages the need of measurable planning to achieve the company's vision and mission. This study took a case study of PT. Gramedia Asri Media, one of the largest retail business in Indonesia. The methodology applied in this study consists of external business analysis, internal business analysis, external IS/IT analysis, and internal IS/IT analysis. The methods assessed to analyze the internal business are the internal value chain, and the Critical Success Factor (CSF), while the PESTLE, five forces, and external value chain analyzes are applied to analyze the external business environment. Furthermore, the method used to analyze the internal environment of IS / TI is the McFarlan Portfolio, while the literature and observation studies are used to conduct analysis of the IT external environment. Assessing the Ward and Peppard methodology, an IS/IT roadmap is aligned with business needs and can be developed within 4 years.
\end{abstract}

Keywords: strategic planning, Ward and Peppard methodology, value chain, McFarlan portfolio 


\section{PENDAHULUAN}

Era informasi dan persaingan global menyebabkan kompetisi semakin ketat. Hal ini mengakibatkan perusahaan harus melakukan terobosan dan inovasi dalam pemanfaatan sarana sistem dan teknologi informasi. Perusahaan dituntut dapat mengikuti perubahan yang terjadi untuk meningkatkan keunggulan bersaing (competitive advantage). Keunggulan bersaing melalui strategi yang kreatif dan tidak mudah diikuti oleh pesaing lainnya akan menjadi peluang untuk meningkatkan keuntungan (profitability) yang terus menerus.

PT. Gramedia Asri Media atau dikenal sebagai Gramedia merupakan perusahaan ritel yang melakukan penjualan alat tulis dan buku sebagai produk utama. Alur bisnis Gramedia mulai dari pembelian barang ke supplier hingga barang sampai ke toko untuk dijual. Tujuan toko Gramedia tercermin dalam visi dan misinya yaitu menjadi perusahaan jaringan ritel dan penerbitan terbesar, tersebar, dan terpadu di Asia Tenggara melalui penyediaan produk berorientasi pasar, layanan unggul, inovatif, dan perilaku bisnis yang beretika.

Gramedia telah berkembang menjadi bisnis dengan jaringan retail yang besar. Masalah yang masih menjadi isu penting adalah potensi kerugian yang disebabkan karena ketidaksesuaian data stok buku di sistem inventori dengan stok aktual. Ketidaksesuaian data antara sistem dengan fisik ini menjadi kendala yang patut menjadi perhatian Gramedia. Hal ini dikarenakan pihak Gramedia harus tetap melakukan pembayaran terhadap fisik buku yang tidak ditemukan kepada supplier.

Gramedia yang tersebar di berbagai daerah mempunyai karakteristik pelanggan yang berbeda. Permasalahan muncul ketika manajemen ingin membuat sebuah promosi yang sesuai dengan situasi dan kondisi pelanggan di masing-masing toko. Ketidaktahuan manajemen dengan apa yang diinginkan pelanggan dapat mengakibatkan loyalitas pelanggan menurun. Hal ini berpotensi adanya penurunan pendapatan Gramedia karena buku yang dijual tidak sesuai dengan karakteristik pelanggan di masing-masing toko.

Proses bisnis Gramedia yang masih belum optimal menjadi kendala bagi perusahaan. Masih banyak para stakeholder yang belum memahami pentingnya kepatuhan terhadap policy, standard, dan procedure dari suatu proses bisnis. Hal ini dapat mengakibatkan terjadinya pengelolaan data dan informasi yang kurang baik. Selain itu, prioritas pengembangan sistem informasi Gramedia belum terencana dengan matang. Ketika ada suatu kebutuhan akan adanya aplikasi baru dalam menjalankan kegiatan operasional perusahaan, tindakan yang dilakukan adalah membuat program bantu untuk memenuhi kebutuhan tersebut tanpa memperhatikan integrasi terhadap aplikasi lain. Dalam jangka pendek, hal tersebut dapat mengatasi masalah, namun dalam jangka panjang akan menimbulkan ketidakserasian integrasi informasi antar unit dalam perusahaan.

Permasalahan-permasalahan yang dihadapi Gramedia saat ini mendorong diperlukannya suatu perencanaan yang matang dan terukur dalam mencapai visi dan misi Gramedia yang telah dicanangkan. Berdasarkan penjelasan di atas, diketahui bahwa perlu suatu perencanaan strategis sistem informasi di Gramedia. Strategi SI/TI yang selaras dengan strategi bisnis perusahaan dapat meningkatkan efisiensi dan efektifitas dalam mencapai visi dan misi perusahaan.

Penelitian perencanaan strategis sistem informasi sudah pernah dilakukan berbagai perusahaan maupun organisasi seperti penelitian yang dilakukan oleh Kardha (2011), Prabhu (2012), Haron dkk (2013), Fadhillah dan Waterkamp (2016), Molly dkk (2017), dan Pranoto dan Widodo (2017). Penelitian Kardha (2011), Prabhu (2012), Haron dkk (2013), dan Pranoto dan Widodo (2017) menggunakan metodologi Ward dan Peppard dalam melakukan perencanaan strategis sistem informasi. Sementara itu, penelitian Fadhillah dan Waterkamp (2016) dan Molly dkk (2017) mengimplementasikan pendekatan balanced scorecard dalam melakukan perencanaan strategis sistem informasi di institusi pendidikan yang menjadi studi kasus penelitian mereka.

Perusahaan manufaktur yang menjadi studi kasus penelitian Haron dkk (2013) menggunakan sistem ERP seperti pada Gramedia yang juga sudah menggunakan sistem ERP pada saat penelitian ini dilakukan. Kardha (2011) melakukan penelitian terhadap PT. Batik Danar Hadi yang bergerak di industri fashion retail batik Indonesia untuk membuat rencana strategis sistem informasi untuk jangka waktu 3 tahun. Sementara itu, PT. Gunung Agung yang menjadi studi kasus penelitian Prabhu (2012) merupakan perusahaan ritel buku seperti halnya Gramedia. Meskipun demikian, berbeda dengan Gramedia yang sudah menggunakan sistem ERP dalam menjalankan bisnis ritel, PT. Batik Danar Hadi maupun PT. Gunung Agung belum menggunakan sistem ERP dalam aktivitas bisnisnya. Penelitiaan Haron (2013) tidak menggunakan analisis eksternal value chain, PESTEL, dan SWOT dalam melakukan analisis kondisi bisnis saat ini. Demikian halnya dengan penelitian Prabhu (2012) tidak menggunakan analisis eksternal value chain dan SWOT. Penelitian ini akan menggunakan metode eksternal value chain, PESTEL, dan SWOT agar permasalahan bisnis ekternal Gramedia dapat dilihat secara lebih detil.

Alur penyelesaian permasalahan pada penelitian ini dimulai dengan melakukan analisis bisnis internal maupun eksternal pada saat ini, dilanjutkan dengan analisis terhadap kondisi sekarang dari SI/TI secara internal dan eksternal 
juga. Setelah itu, bisnis dan SI/TI pada masa mendatang dianalisis baik secara internal maupun eksternal. Metodologi Ward dan Peppard digunakan penelitian ini pada tahapan analisis bisnis dan SI/TI, serta dalam perencanaan strategis sistem informasi. Metode internal value chain, dan Critical Success Factor diaplikasikan untuk menganalisis bisnis internal Gramedia, sedangkan metode untuk analisis bisnis eksternal adalah eksternal value chain, five forces, dan PESTEL. Analisis SWOT digunakan untuk mengetahui kondisi saat ini Gramedia dan menyusun rencana mendatang terhadap bisnis yang akan dijalankan. Metode yang digunakan untuk menganalisis internal SI/TI adalah Portofolio McFarlan, sementara itu studi literatur dan observasi digunakan untuk melakukan analisis eksternal SI/TI. Hasil dari penelitian ini diharapkan dapat memberikan kontribusi terhadap penyelesaian masalah yang dihadapi Gramedia pada saat ini. Selain itu, penelitian ini akan menghasilkan roadmap SI/TI dalam jangka waktu 4 tahun ke depan yang selaras dengan bisnis Gramedia di masa mendatang.

\section{TINJAUAN PUSTAKA}

Pendekatan Ward dan Peppard digunakan pada penelitian ini bertujuan untuk menyelaraskan visi misi perusahaan dengan strategis sistem informasi menggunakan berbagai metode dalam melakukan analisis kondisi bisnis dan SI/TI. Pemahaman terkait strategi bisnis yang dijalankan suatu organisasi sangat mempengaruhi strategi SI/TI yang akan diterapkan oleh organisasi tersebut (Hadi dan Prihadi, 2010). Ketika organisasi sudah menginvestasikan SI/TI pada waktu lampau tetapi tidak berdampak positif bagi tujuan bisnis organisasi tersebut (terutama dalam meningkatkan keunggulan kompetitif dan melihat peluang bisnis), maka metodologi Ward dan Peppard ini dapat mulai digunakan untuk menganalisis kondisi tersebut (Ward dan Peppard, 2002). Perencanaan strategis sistem informasi dengan hanya berfokus pada teknologi tanpa melihat kebutuhan bisnis dari organisasi akan mengakibatkan investasi sistem informasi menjadi tidak bermanfaat.

Penerapan sistem informasi dan teknologi informasi suatu organisasi memiliki 3 sasaran utama, yaitu: perbaikan efisiensi kerja dengan cara otomasi dalam aktivitas bisnis (O’Brien dan Markas, 2007), menyediakan informasi yang lengkap dalam pengambilan keputusan, serta peningkatan keunggulan kompetitif organisasi (Ward dan Peppard, 2002). Untuk mencapai sasaran utama tersebut, perencanaan strategis sistem informasi membutuhkan suatu metodologi yang menyelaraskan kebutuhan organisasi dengan strategi SI/TI sebagaimana yang dibuat oleh Ward dan Peppard. Alur metodologi ini dapat dilihat pada Gambar 1.

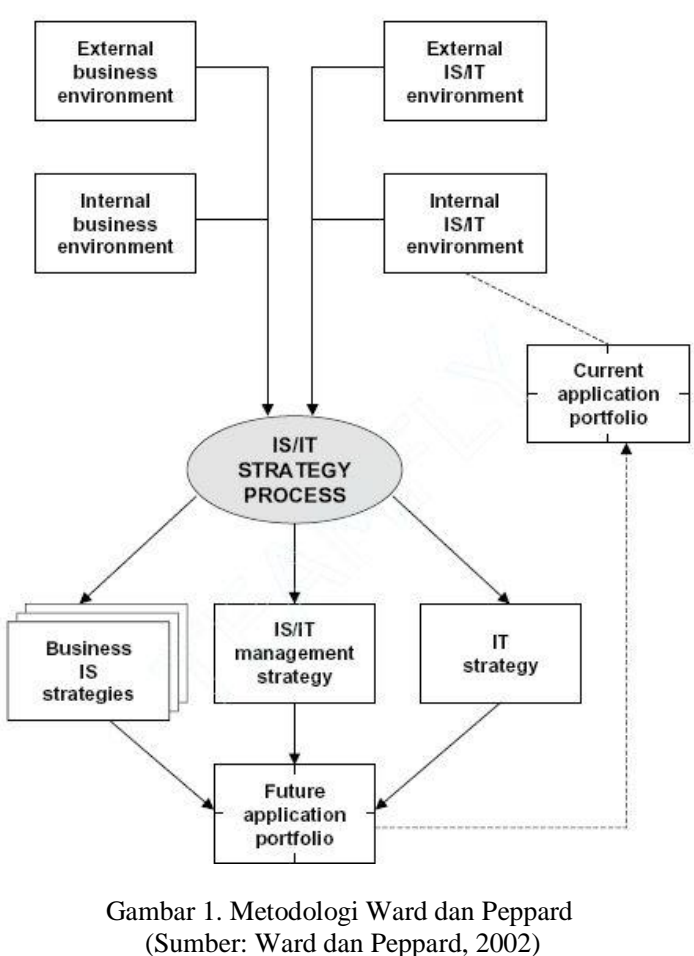

Input dari pemodelan pada Gambar 1 adalah sebagai berikut (Ward dan Peppard, 2002):

a. Analisis bisnis eksternal

Iklim industri, iklim ekonomi, dan iklim kompetitif di mana organisasi berada dianalisis pada tahap ini.

b. Analisis bisnis internal

Tujuan, strategi bisnis sekarang ini, nilai bisnis, budaya, proses dan sumber daya dari organisasi.

c. Analisis eksternal SI/TI

Peluang maupun penggunaan TI serta tren teknologi yang dijalankan pihak lain, terutama pelanggan, pesaing, dan pemasok.

d. Analisis internal SI/TI

Perspektif TI saat ini dalam bisnis, cakupan bisnis, dan kontribusi terhadap pencapaian tujuan organisasi, infrastruktur teknologi, sumber daya, serta keterampilan. Portofolio aplikasi pada saat ini dari sistem yang sudah ada serta sistem yang masih dalam pengembangan juga merupakan bagian dari lingkungan internal SI/TI.

\section{METODOLOGI PENELITIAN}

Tahapan pada penelitian perencanaan strategis sistem informasi terdiri dari 3 tahap, yaitu analisis kondisi sekarang pada Gambar 2, analisis kondisi masa mendatang pada Gambar 3, serta analisis kesenjangan dan pembuatan roadmap dapat dilihat pada Gambar 4. 


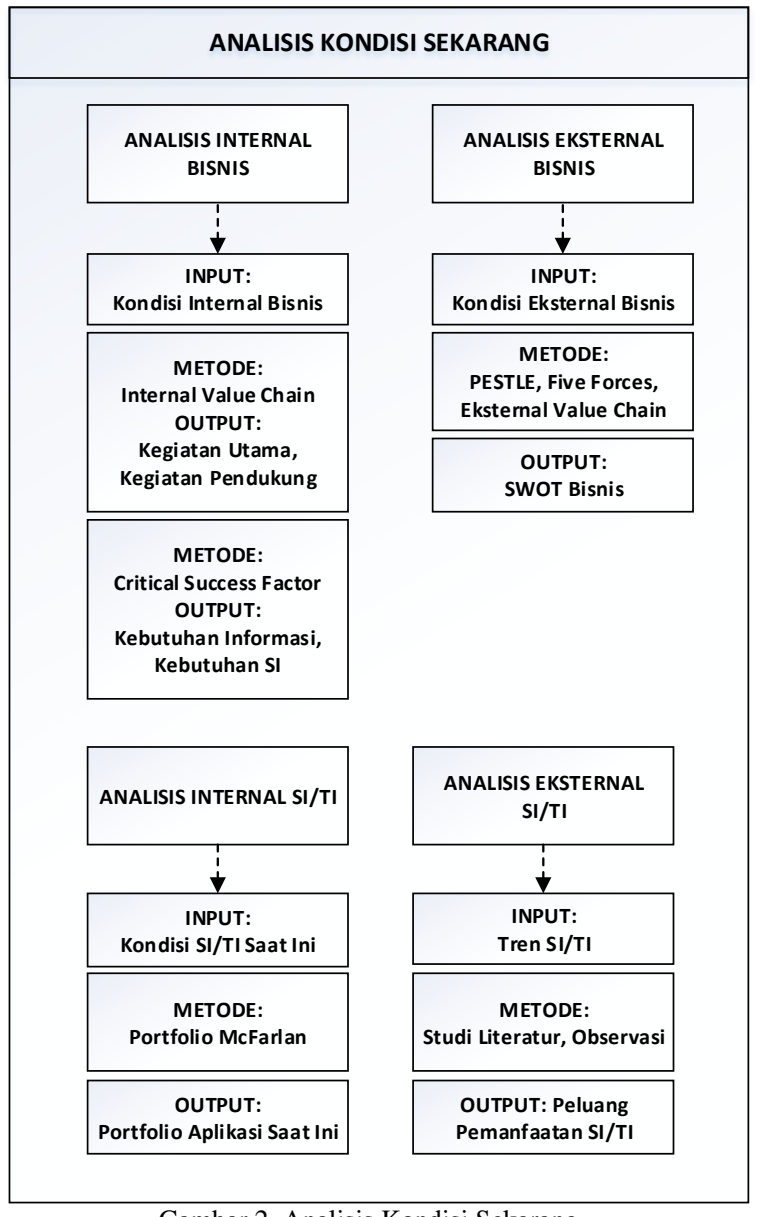

Gambar 2. Analisis Kondisi Sekarang

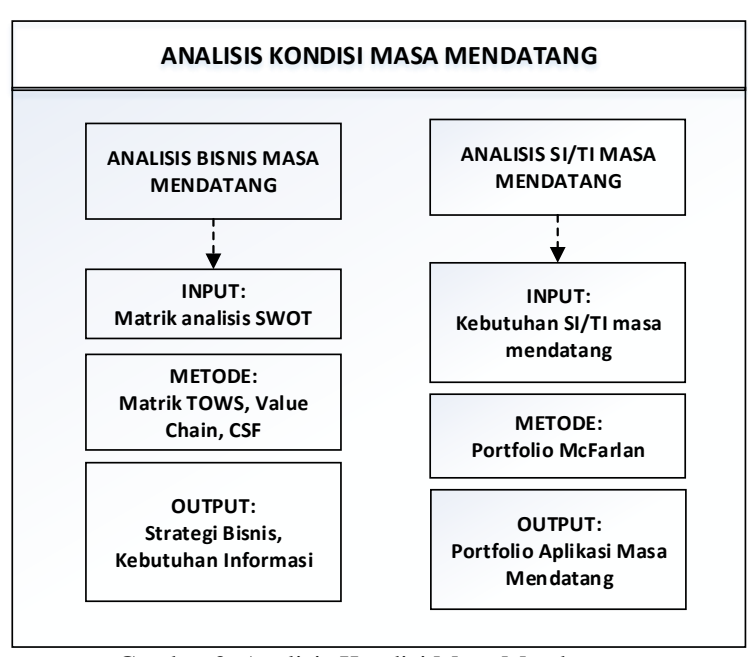

Gambar 3. Analisis Kondisi Masa Mendatang

Berikut penjelasan lebih lanjut metode yang digunakan untuk analisis data dan pengumpulan data pada penelitian ini.

\subsection{Metode Analisis Data}

Alat dan teknik yang digunakan untuk menganalisis perencanaan strategis sistem informasi pada Gramedia adalah sebagai berikut:

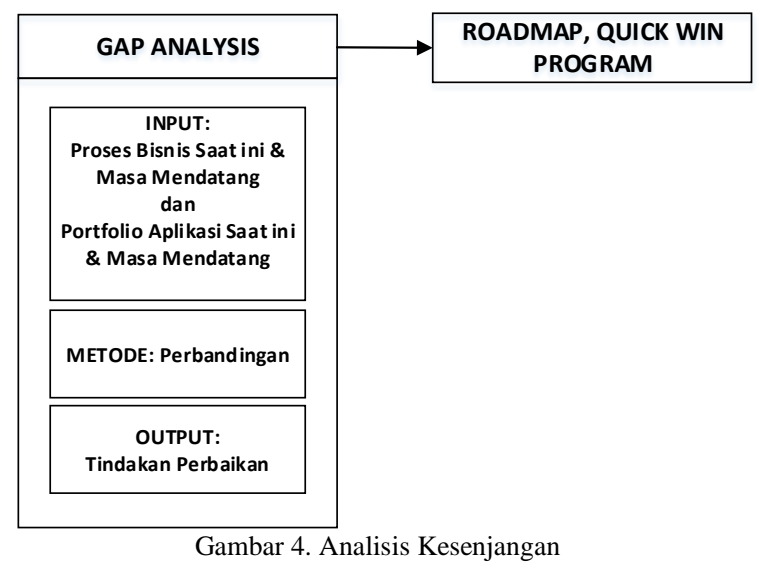

a. Analisis Internal Value Chain

Analisis value chain internal, yaitu analisis terhadap segala aktivitas perusahaan yang terbagi menjadi kegiatan utama dan kegiatan pendukung pada unit bisnis (Ward dan Peppard, 2002).

b. Analisis Critical Success Factor (CSF)

Analisis CSF bertujuan untuk menafsirkan tujuan bisnis berkenaan dengan tindakan yang dibutuhkan untuk mencapai tujuan tersebut, informasi kunci dan kebutuhan aplikasi dari organisasi dan manajernya, dan untuk mengetahui adanya kelemahan serta kekuatan pada sistem yang dimiliki organisasi pada kondisi sekarang (Ward dan Peppard, 2002). Selain itu, analisis CSF dilakukan untuk mengetahui area kunci agar organisasi maupun perusahaan dapat berkembang.

c. Analisis PESTLE (Politic, Economy, Social, Technology, Legal, Environment)

Analisis ini digunakan untuk mengetahui pengaruh lingkungan eksternal bisnis. Ada 4 faktor yang ditinjau dengan analisis ini, yaitu Politik, Ekonomi, Sosial, Teknologi, Legal, dan Lingkungan. Analisis ini akan digunakan untuk menentukan strategi mendatang.

d. Analisis Five Forces

Five Forces awalnya dikembangkan oleh Porter, terdiri dari daya tawar pemasok, daya tawar pelanggan, ancaman dari pendatang baru, ancaman dari barang pengganti, serta persaingan antara para kompetitor (Pham dkk, 2013). Agar perusahaan yang termasuk dalam suatu industri dapat berhasil, perusahaan tersebut harus dapat menghadapi kekuatan kompetitif yang ada dalam industri tersebut secara efektif (Ward dan Peppard, 2002). Oleh karena itu, faktor-faktor yang berpengaruh terhadap kekuatan kompetitif dibutuhkan analisis lebih mendalam.

e. Analisis Eksternal Value Chain

Berdasarkan konsep value chain yang dijelaskan oleh Porter, bisnis unit merupakan mata rantai dari perusahaan, sedangkan suatu perusahaan merupakan salah satu mata rantai dari industri secara keseluruhan. Dengan demikian, yang perlu dilakukan adalah melakukan analisis eksternal 
value chain untuk menentukan posisi perusahaan pada industri.

f. Portfolio Aplikasi McFarlan

Portfolio aplikasi McFarlan mengelompokkan aplikasi berdasarkan kontribusinya terhadap kondisi organisasi saat ini dan kondisi organisasi pada masa mendatang ke dalam 4 area, yaitu key operational, support, strategic, dan high potential (Ward dan Peppard, 2002).

g. Analisis Strength, Weakness, Opportunities, Threat (SWOT)

Analisis ini bertujuan untuk mengidentifikasi kekuatan dan kelemahan dari organisasi, serta peluang dan ancaman terhadap bisnis. Organisasi mampu meningkatkan serta mempertahankan daya saing dengan memahami kekuatan yang dimiliki. Selain itu, kerugian dapat dikurangi dengan memperbaiki kelemahan yang dimiliki organisasi. Analisis SWOT dapat digunakan untuk mengetahui kondisi saat ini dari organisasi dan menyusun rencana mendatang.

\subsection{Metode Pengumpulan Data}

Pembahasan dari masing-masing metode pengumpulan data dijelaskan pada bagian dibawah ini:

a. Studi Literatur

Studi literatur dilakukan berkaitan dengan teori yang digunakan dalam perencanaan strategis sistem informasi, dimana merupakan metode untuk menganalisis lingkungan bisnis dan SI/TI.

b. Wawancara

Wawancara dilakukan dengan pihak di dalam organisasi yang memegang peranan dalam pemanfaatan teknologi informasi di Gramedia, yaitu General Manager SIT Division.

c. Observasi

Pengamatan aktivitas atau kegiatan yang berhubungan dengan proses bisnis Gramedia dilakukan dengan metode observasi, terutama dalam proses pembelian dan penjualan buku dari supplier sampai ke customer. Selain itu, dilakukan observasi terhadap manajemen SI/TI, sistem informasi yang digunakan, spesifikasi hardware dan server, serta infrastruktur TI saat ini.

\section{HASIL DAN PEMBAHASAN}

Pembahasan penelitian ini terbagi menjadi 5, yaitu analisis bisnis pada kondisi sekarang, analisis SI/TI pada kondisi sekarang, analisis bisnis pada masa mendatang, analisis SI/TI pada masa mendatang, serta analisis kesenjangan dan pembuatan roadmap.

\subsection{Analisis Bisnis pada Kondisi Sekarang}

Visi dan misi Gramedia adalah "Menjadi perusahaan jaringan ritel dan penerbitan terbesar, tersebar, dan terpadu di Asia Tenggara melalui penyediaan produk berorientasi pasar, layanan unggul, inovatif, dan perilaku bisnis yang beretika" (GoRP Kompas Gramedia, 2015).

Struktur organisasi Gramedia terdiri dari Corporate Secretary, Internal Audit, dan 5 direktorat, yaitu:

- Publishing \& Education, membawahi penerbit buku Kompas, M\&C, Grasindo, BIP, Elex Media Komputindo, KPG, Gramedia Pustaka Utama, ELTI, dan BSW.

- Operation, membawahi toko Gramedia regular, speciality store (Gramedia Kids, Teeny Teensy), dan e-business (Gramedia.com).

- Marketing \& Merchandising, membawahi Merchandising, Marketing, Distribution, dan Sales Non GAM

- Business Development, Human \& Resources, dan Facility Management

- SIT \& Finance, membawahi Finance \& Accounting, dan System \& IT

Alur bisnis Gramedia yang dimulai dari pembelian barang ke supplier hingga barang sampai ke toko untuk dijual terlihat pada Gambar 5. Berdasarkan struktur organisasi serta visi misi Gramedia, dibuatlah internal value chain yang terdiri atas kegiatan utama dan kegiatan pendukung yang dapat dilihat pada Gambar 6.

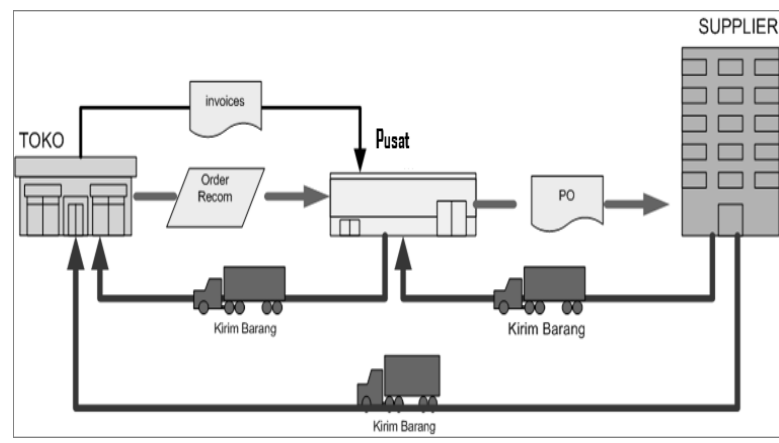

Gambar 5. Proses Bisnis Gramedia

(Sumber: GoRP Kompas Gramedia, 2015)

Kegiatan inbound logistic di internal value chain Gramedia adalah proses pemesanan produk yang akan dijual ke supplier. Pada kegiatan ini, jumlah dan jenis produk yang dipesan akan dicatat ke dalam sistem pemesanan dan Gramedia akan mengeluarkan purchase order sebagai bukti pemesanan. Pemesanan produk dapat dikelompokkan menjadi dua kategori, yaitu pemesanan produk baru dan restok produk. Pemesanan produk baru dilakukan berdasarkan hasil riset yang dilakukan oleh unit Merchandising, sedangkan restok produk dilakukan pada saat ada permintaan dari toko.

Kegiatan operasional yang dilakukan oleh Gramedia adalah mendistribusikan produk yang dipesan ke warehouse atau langsung ke toko. Data produk yang dikirimkan oleh supplier akan dicatat ke dalam sistem Gramedia. Selanjutnya setelah barang diterima, data dan jumlah barang yang diterima juga akan dicatat ke dalam sistem 
Gramedia. Dengan demikian, proses rekonsiliasi data yang dipesan, dikirim, dan diterima akan dapat dilakukan.

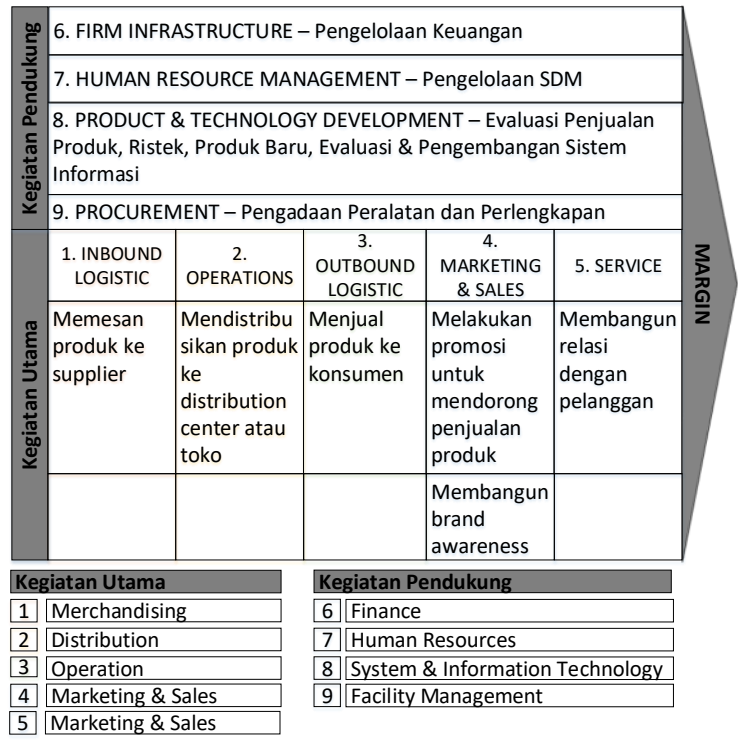

Gambar 6. Internal Value Chain Gramedia

Kegiatan outbound logistic Gramedia adalah penjualan produk ke konsumen. Konsumen dapat membeli produk Gramedia dengan langsung berkunjung ke toko yang ada ataupun melalui toko online. Seluruh transaksi yang terjadi akan dicatat ke dalam sistem keuangan.

Kegiatan sales \& marketing di internal value chain Gramedia, yaitu melakukan promosi untuk mendorong penjualan produk dan membangun brand awareness. Proses promosi diawali dengan perencanaan promosi yang akan dilakukan, kemudian diikuti oleh pemasangan iklan di media berdasarkan rencana tersebut. Selanjutnya akan dilakukan evaluasi terhadap promosi tersebut.

Kegiatan service berkaitan dengan upaya membangun loyalitas pelanggan. Saat ini, pelanggan yang ada dirasa masih kurang loyal sehingga perlu dilakukan tindakan untuk menaikkan loyalitas pelanggan. Berdasarkan data Customer Relationship Management Gramedia, jumlah member pada bulan Januari 2016 - Juli 2016 mengalami kenaikan sebanyak 68.587 orang, tetapi transaksi buku yang dilakukan member justru mengalami penurunan. Total transaksi buku oleh member Gramedia pada bulan Juli 2016 mengalami penurunan sembilan milyar rupiah sejak bulan Januari 2016 (Rumiarti dan Budi, 2016). Semakin banyaknya jasa penjualan buku online mengakibatkan pelanggan tidak merasa perlu untuk membeli buku dari Gramedia. Untuk itu diperlukan adanya strategi yang meningkatkan keunggulan Gramedia terhadap saingannya.

Berdasarkan hasil observasi dan wawancara dengan General Manager SIT Division Gramedia, terdapat permasalahan pada masing-masing aktivitas utama seperti terlihat pada Tabel 1 .
Tabel 1. Permasalahan pada Kegiatan Utama

\begin{tabular}{ll}
\hline \multicolumn{1}{c}{ Proses } & \multicolumn{1}{c}{ Permasalahan } \\
\hline Inbound Logistic & Lambat dalam melakukan restok \\
& produk sehingga toko kehabisan \\
& produk yang masih banyak dicari \\
& oleh konsumen \\
& Jumlah dan/atau jenis barang yang \\
& diterima toko berbeda dengan yang \\
dipesan pperation & Ada perbedaan harga antara harga \\
& pada label dengan harga pada \\
& sistem inventori \\
& Jumlah produk pada sistem \\
& inventori tidak sesuai dengan \\
& jumlah aktual produk di toko \\
Outbound Logistic & - \\
& Pelanggan kurang loyal akibat \\
Marketing \& Sales & semakin bertambahnya saingan \\
Tervice &
\end{tabular}

Pada analisis eksternal value chain, Gramedia merupakan perusahaan yang berada pada posisi retailer/distributor. Seperti terlihat pada Gambar 7, bisnis yang dilakukan oleh Gramedia adalah membeli produk-produk dari berbagai macam pemasok, untuk selanjutnya dijual kepada konsumen melalui toko buku yang tersebar di seluruh Indonesia, ataupun dijual melalui toko online Gramedia.

Berdasarkan analisis mengenai kondisi lingkungan internal bisnis dan eksternal bisnis pada Gramedia menggunakan value chain, CSF, PESTLE dan five forces, maka dapat diperoleh kekuatan (strength), kelemahan (weakness), peluang (opportunity), dan ancaman (threat). Pemetaan SWOT berdasarkan lingkungan bisnis yang dapat dilihat pada Tabel 2. SWOT ini nantinya dijadikan dasar untuk menentukan strategi bisnis.

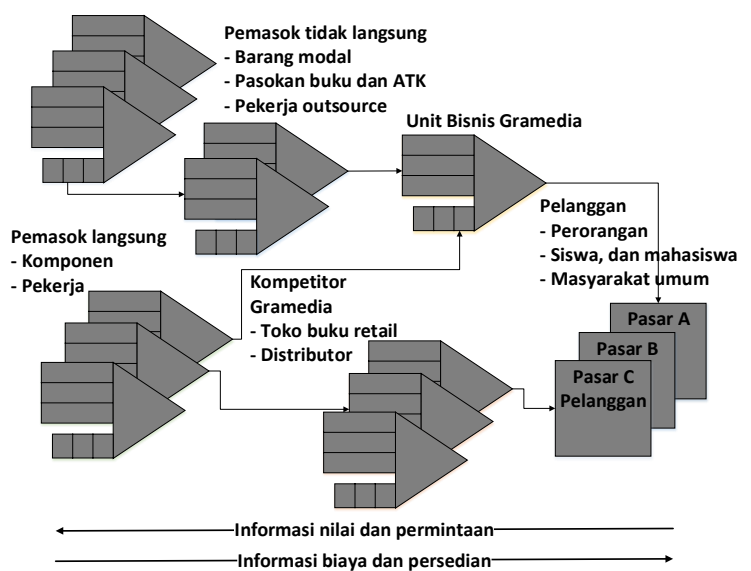

Gambar 7. Eksternal Value Chain Gramedia

Tabel 2. Pemetaan SWOT

\begin{tabular}{|l|l|}
\hline \multicolumn{1}{|c|}{ Strength } & \multicolumn{1}{c|}{ Weakness } \\
\hline [S1] Brand Gramedia sudah & [W1] Produk buku yang \\
cukup dikenal. & ditawarkan Gramedia relatif \\
[S2] Gramedia terus & sama dengan toko buku lain. \\
melakukan inovasi untuk & [W2] Harga buku yang \\
menarik minat customer & ditawarkan Gramedia relatif \\
datang ke toko buku. & lebih mahal dibandingkan toko \\
[S3] Gramedia memiliki & buku lain. \\
\hline
\end{tabular}




\begin{tabular}{|c|c|}
\hline $\begin{array}{l}\text { modal yang cukup besar } \\
\text { untuk mengembangkan } \\
\text { bisnis ritel buku. } \\
\text { [S4] Gramedia memiliki } \\
\text { cabang di kota-kota besar. }\end{array}$ & \\
\hline Opportunity & Threat \\
\hline $\begin{array}{l}\text { [O1] Program wajib belajar } \\
9 \text { tahun yang telah } \\
\text { dicanangkan pemerintah. } \\
\text { [O2] Kebijakan pemerintah } \\
\text { dalam menyelenggarakan } \\
\text { pendidikan. } \\
\text { [O3] Pemerintah } \\
\text { mempersingkat perizinan } \\
\text { investasi. } \\
\text { [O4] Kemudahan akan } \\
\text { teknologi mobile yang telat } \\
\text { berkembang pesat. } \\
\text { [O5] Peraturan UU Nomor } \\
\text { 19 Tahun 2002 tentang UU } \\
\text { Hak Cipta. } \\
\text { [O6] Jumlah customer yang } \\
\text { meningkat pada waktu } \\
\text { tertentu, misalnya: tahun } \\
\text { ajaran baru. }\end{array}$ & $\begin{array}{l}\text { [T1] Pemerintah tetapkan } \\
\text { peraturan kenaikan upah buruh } \\
\text { berlaku seluruh wilayah } \\
\text { Indonesia kecuali } 8 \text { provinsi. } \\
\text { [T2] Kenaikan nilai inflasi. } \\
\text { [T3] Kenaikan harga bahan } \\
\text { bakar minyak. } \\
\text { [T4] Melemahnya kurs nilai } \\
\text { tukar rupiah terhadap dollar. } \\
\text { [T5]Minat baca masyarakat } \\
\text { Indonesia masih rendah. } \\
\text { [T6] Rentan konflik pada } \\
\text { beberapa wilayah Indonesia. } \\
\text { [T7] Kematangan infrastruktur } \\
\text { daerah tertentu belum } \\
\text { memadai. } \\
\text { [T8] Semua transaksi } \\
\text { pembayaran wajib } \\
\text { menggunakan mata uang } \\
\text { rupiah. } \\
\text { [T9] Ada kecenderungan } \\
\text { customer untuk beralih ke } \\
\text { produk pengganti yang mudah } \\
\text { didapatkan, misal: } e \text {-book. } \\
\text { [T10] Adanya toko buku online } \\
\text { yang menawarkan pembelian } \\
\text { buku secara online. }\end{array}$ \\
\hline
\end{tabular}

\subsection{Analisis SI/TI pada Kondisi Sekarang}

Analisis SI/TI terdiri dari analisis internal SI/TI dan analisis eksternal SI/TI. Analisis internal SI/TI terkait dengan organisasi SI/TI, aplikasi SI, dan infrastruktur TI untuk mendukung proses bisnis saat ini. Analisis eksternal SI/TI terkait dengan tren teknologi saat ini yang dapat dimanfaatkan oleh Gramedia untuk meningkatkan nilai tambah strategi bisnis.

Organisasi dan manajemen SI/TI di Gramedia menjadi tanggung jawab System \& Information Technology Division yang membawahi 2 department yaitu: Unit Technical Service \& Help Desk Unit Department bertugas melakukan perencanaan, pengembangan dan pemeliharaan sistem jaringan, server, dan hardware agar dapat optimal mendukung jalannya bisnis; Unit System Analyst \& Development Department bertugas member rekomendasi solusi, melakukan pengembangan dan pemeliharaan sistem dan software untuk menjawab kebutuhan perusahaan, termasuk di dalamnya analisis biaya, desain sistem, dan timeline proyek.

Gambar 8 menunjukkan keterkaitan aliran data pada aplikasi utama yang mendukung proses bisnis di Gramedia, yaitu mulai dari pembelian barang, penjualan barang di toko, pembukuan/pencatatan transaksi penjualan, hingga menampilkan report data penjualan untuk pengambilan keputusan berkaitan dengan bisnis. Aplikasi yang digunakan Gramedia sudah saling terintegrasi, tetapi masih terdapat program bantu yang dibuat untuk mempermudah pengguna dalam melakukan aktivitas pekerjaannya sehari-hari.

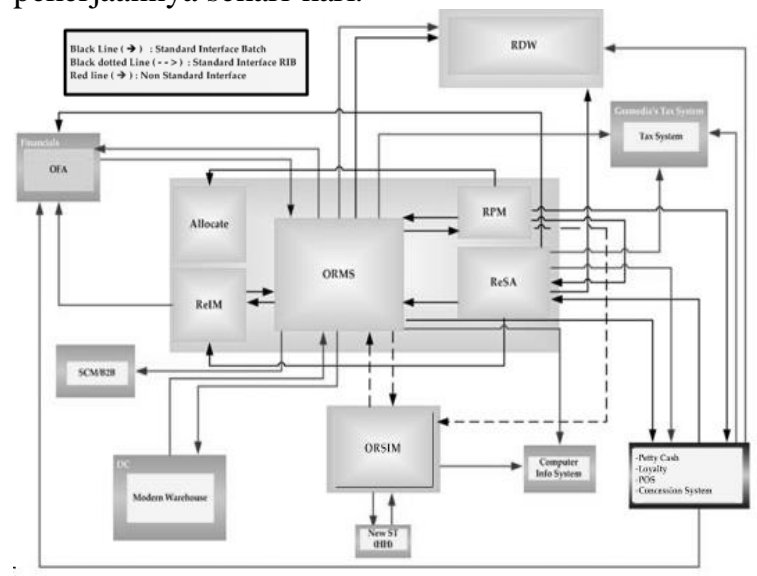

Gambar 8. Aliran Data Antar Aplikasi pada Proses Bisnis Gramedia

(Sumber: GoRP Kompas Gramedia, 2015)

Selain itu, masih terdapat modifikasi interface yang merupakan standar dari Oracle. Hal ini dilakukan untuk menyesuaikan data yang dibutuhkan oleh Gramedia saat ini.

Keseluruhan aplikasi yang saat ini digunakan Gramedia dikelompokkan pada matrik portofolio McFarlan seperti terlihat pada Tabel 3. Analisis portofolio McFarlan digunakan untuk mengelompokkan aplikasi pada sebuah portofolio berdasarkan peran dan fungsinya pada perusahaan, yaitu high potential, strategic, key operational, maupun support. Terdapat 7 aplikasi berada pada kuadran support, 8 aplikasi pada kuadran key operation, dan 1 aplikasi pada kuadran high potential.

Tabel 3. Matrik Portfolio McFarlan Gramedia - Current Condition

\begin{tabular}{ll}
\hline Strategic & High Potential \\
\hline & RDW \\
\hline Key Operational & Support \\
\hline RMS & CO \\
REIM & BI Publisher \\
SIM & Info Product \\
RESA & SOA Unit \\
POS & GAM Portal \\
RPM & HR Portal \\
BO & HR Dev Application \\
Oracle Finance &
\end{tabular}

Infrastruktur teknologi informasi yang dimiliki Gramedia digunakan untuk mendukung sistem informasi yang dimiliki saat ini. Server yang digunakan Gramedia terbagi menjadi 2 bagian utama, yaitu server toko dan server pusat. Selain itu, infrastruktur TI Gramedia sudah memiliki sistem keamanan khusus yang digunakan baik berupa hardware seperti firewall maupun software seperti antivirus. Setiap komputer harus menggunakan proxy untuk terhubung ke internet. Penggunaaan anti virus bernama ESET di seluruh unit dan toko sudah dilakukan update secara terpusat. Pengguna tidak perlu melakukan update secara manual, jika server 
ESET melakukan update maka client ESET pada tiap komputer juga ter-update.

Gramedia bekerjasama dengan Indosat dan Telkom untuk menghubungkan seluruh server Gramedia yang berlokasi di seluruh Indonesia. Unit yang berlokasi di area Jakarta menggunakan jaringan Telkom IPVPN, dan IM2, sedangkan unit dan toko yang berlokasi di luar Jakarta menggunakan jaringan Telkom IPVPN dan juga Telkom Speedy Cloud.

Infrastruktur jaringan yang digunakan oleh Gramedia dinilai sudah cukup memadai. Hal ini karena sejak tahun 2008/2009 sudah dilakukan perbaikan infrastruktur bersamaaan dengan implementasi Oracle Retail. Perbaikan infrastruktur jaringan ini dilakukan untuk menunjang seluruh proses bisnis toko dengan kantor pusat menjadi terpusat.

Analisis eksternal SI/TI dilakukan untuk memahami teknologi yang saat ini sedang berkembang. Dengan mengetahui tren TI saat ini, Gramedia dapat memanfaatkannya untuk diimplementasikan dalam menyelaraskan dengan strategi bisnis Gramedia sehingga meningkatkan nilai tambah.

Berdasarkan tren IT strategic yang dikemukan pada web Forbes (2015) dan tren saat ini di Indonesia, kemudian dilakukan analisis pemanfaatan tren TI yang digunakan di Gramedia dapat dilihat pada Tabel 4.

\begin{tabular}{|c|c|}
\hline Tren TI & Keterangan \\
\hline Big Data & $\begin{array}{l}\text { Data warehouse sudah ada namun perlu } \\
\text { dikelola terhadap data yang besar lagi. Data } \\
\text { mining perlu diterapkan untuk dapat } \\
\text { menganalisis data penjualan dan customer } \\
\text { potensial Gramedia. }\end{array}$ \\
\hline ERP & $\begin{array}{l}\text { Penerapan ERP di toko Gramedia sudah ada } \\
\text { mulai tahun } 2009 \text { namun hal ini sudah } \\
\text { melebihi } 5 \text { tahun penggunaanya sehingga } \\
\text { diperlukan evaluasi terkait kelayakan umur } \\
\text { perangkat TI. }\end{array}$ \\
\hline$C R M$ & $\begin{array}{l}\text { Penerapan CRM di toko Gramedia belum } \\
\text { dilakukan, padahal ini sangat penting untuk } \\
\text { melakukan analisis kebuuhan dan pelayanan } \\
\text { terhadap pelanggan. }\end{array}$ \\
\hline Mobile & Penerapan aplikasi mobile di toko Gramedia \\
\hline Apllication & $\begin{array}{l}\text { belum sepenuhnya diterapkan. Nantinya } \\
\text { dengan aplikasi ini memudahkan pelanggan } \\
\text { dalam melayani dirinya sendiri (self-sevices) }\end{array}$ \\
\hline Web & Penerapan aplikasi berbasis web di toko \\
\hline Application & $\begin{array}{l}\text { Gramedia menjadi hal yang strategis. Tren } \\
\text { Internet of Thing saat ini ikut membantu } \\
\text { penjualan secara offline dalam pemasaran. }\end{array}$ \\
\hline
\end{tabular}

\subsection{Analisis Bisnis pada Masa Mendatang}

Analisis strategi bisnis dilakukan berdasarkan analisis SWOT dan analisis internal value chain. Analisis SWOT digunakan untuk menentukan rencana bisnis mendatang. Analisis internal value chain digunakan untuk memperbaiki proses bisnis saat ini. Berdasarkan analisis SWOT, dilakukan matrikulasi terhadap hasil pemetaan tersebut yang dapat dilihat pada Tabel 5.
Tabel 5. Matriks SWOT Bisnis

\begin{tabular}{ll}
\multicolumn{1}{c}{$\begin{array}{c}\text { Strategi Strength- } \\
\text { Opportunity }\end{array}$} & \multicolumn{1}{c}{$\begin{array}{c}\text { Strategi Weakness- } \\
\text { Opportunity }\end{array}$} \\
\hline [SO1] Meningkatkan promosi & [WO1] Mengembangkan \\
ke lembaga pendidikan & produk selain buku/ATK \\
[S1],[O1],[O2],[O6] & [W1], [O3] \\
\hline [SO2] Mengembangkan retail- & \\
retail baru di tempat-tempat & \\
strategis di kota besar di & \\
Indonesia [S3],[S4],[O3] & \\
\hline [SO3] Mengembangkan & \\
pangsa pasar ke luar negeri & \\
[S3],[O4]
\end{tabular}

\begin{tabular}{|c|c|}
\hline Strategi Strength- Threat & $\begin{array}{c}\text { Strategi Weakness - } \\
\text { Threat }\end{array}$ \\
\hline $\begin{array}{l}\text { [ST1] Mengembangkan } \\
\text { fasilitas untuk menarik minat } \\
\text { customer berkunjung ke toko } \\
\text { Gramedia [S2],[T9], [T10] }\end{array}$ & $\begin{array}{l}\text { [WT1] Mengadakan bazar } \\
\text { buku untuk menjual stok } \\
\text { buku lama } \\
{[\mathrm{W} 2],[\mathrm{T} 1],[\mathrm{T} 2],[\mathrm{T} 3],[\mathrm{T} 4]}\end{array}$ \\
\hline $\begin{array}{l}\text { [ST2] Mengembangkan } \\
\text { pelayanan mandiri bagi } \\
\text { pengunjung toko buku } \\
\text { sehingga staff dapat bekerja } \\
\text { dengan lebih efisien } \\
{[\mathrm{S} 2],[\mathrm{T} 1],[\mathrm{T} 2],[\mathrm{T} 3],[\mathrm{T} 4]} \\
\end{array}$ & $\begin{array}{l}\text { [WT2] Mengadakan } \\
\text { pameran buku untuk } \\
\text { memperkenalkan produk } \\
\text { baru [W2], [T5] }\end{array}$ \\
\hline & $\begin{array}{l}\text { [WT3] Meningkatkan } \\
\text { loyalitas pelanggan } \\
[\mathrm{W} 1],[\mathrm{W} 2], \mathrm{T} 9]\end{array}$ \\
\hline
\end{tabular}

Berdasarkan strategi bisnis hasil pemetaan SWOT kemudian dilakukan pemetaan terhadap aktivitas di value chain dan proses bisnis Gramedia di masa mendatang. Pada hasil analisis value chain kondisi saat ini dilakukan perubahan rangkaian proses untuk dapat mengatasi masalah yang ada terlihat pada Gambar 9.

Pada proses inbound logistic di masa mendatang, untuk mempercepat proses restock diperlukan adanya mekanisme pemberitahuan apabila stok produk sudah menipis. Dengan demikian, pemesanan dapat dilakukan sebelum stok habis. Ketersediaan stok produk di toko akan terjaga dengan adanya mekanisme ini.

Pada proses outbound logistic di masa mendatang, untuk mengatasi masalah perbedaan harga pada label produk dengan harga pada sistem, diperlukan adanya mekanisme pemberitahuan apabila ada perubahan harga pada sistem. Dengan demikian, toko dapat segera mengganti label harga produk sesuai dengan harga baru pada sistem.

Berdasarkan hasil analisis internal value chain, diperoleh permasalahan pada aktivitas yang berjalan saat ini. Solusi bisnis yang ditempuh untuk menyelesaikan permasalahan pada internal value chain seperti terlihat pada Tabel 6 .

\subsection{Analisis SI/TI pada Masa Mendatang}

Berdasarkan solusi kebutuhan sistem informasi yang diperoleh, kemudian dilakukan pemetaan aplikasi masa mendatang berdasarkan analisis SWOT, dan value chain. Mengacu kepada solusi bisnis yang diperoleh dari analisis internal value chain, diperoleh solusi SI/TI seperti pada Tabel 7. 
Solusi sistem informasi kemudian dipetakan ke dalam matrik portofolio McFarlan berdasarkan peran dan fungsinya bagi perusahaan, yaitu support, key operational, high potential, serta strategic seperti terlihat pada Tabel 8 .

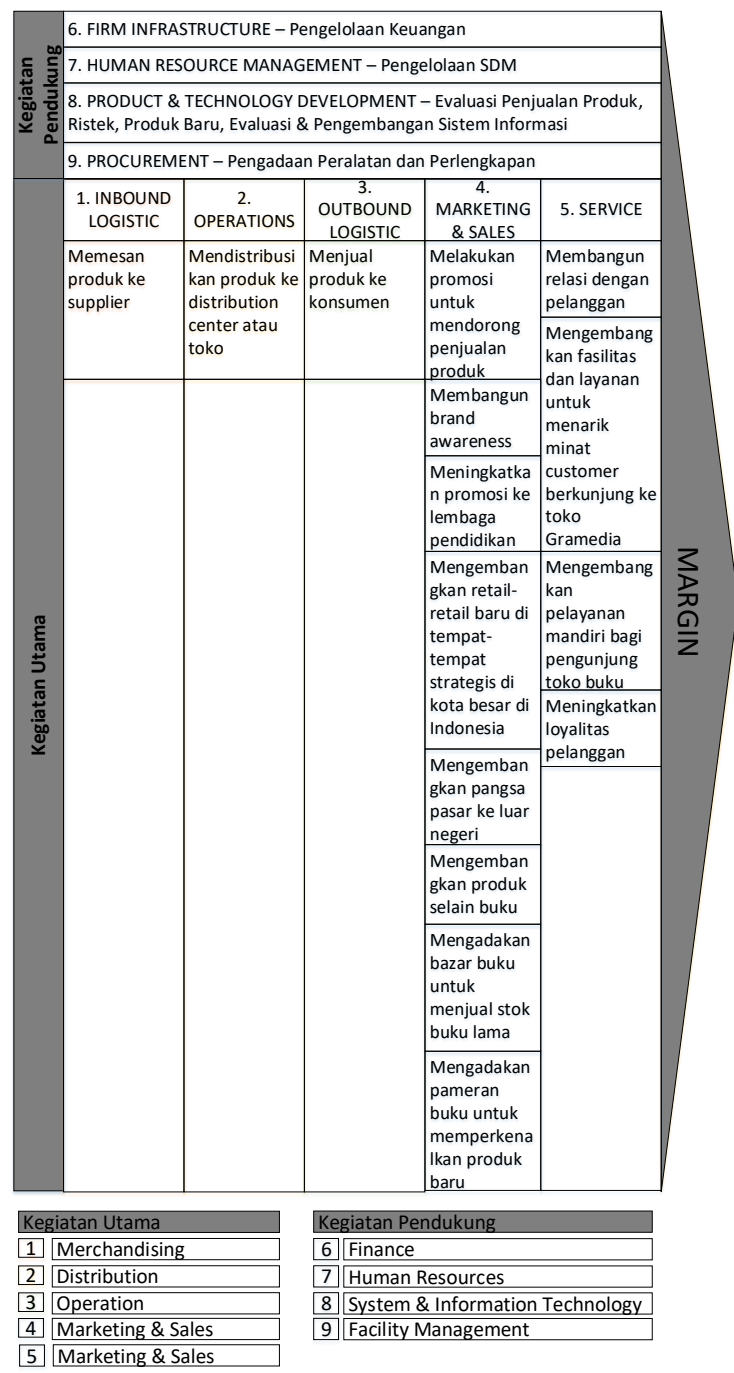

Gambar 9. Value Chain Future Condition

Tabel 6. Solusi Bisnis pada Internal Value Chain

\begin{tabular}{ll}
\hline \multicolumn{1}{c}{ Masalah } & \multicolumn{1}{c}{ Solusi Bisnis } \\
\hline $\begin{array}{l}\text { Keterlambatan proses } \\
\text { restok }\end{array}$ & $\begin{array}{l}\text { Ada peringatan apabila } \\
\text { jumlah stok produk } \\
\text { berkurang hingga jumlah } \\
\text { tertentu }\end{array}$ \\
$\begin{array}{l}\text { Perbedaan jumlah } \\
\text { produk yang dipesan } \\
\text { dan diterima oleh toko }\end{array}$ & $\begin{array}{l}\text { Ada konfirmasi penerimaan } \\
\text { dan pengiriman produk }\end{array}$ \\
$\begin{array}{l}\text { Perbedaan antara } \\
\text { harga pada label } \\
\text { dengan harga pada } \\
\text { sistem }\end{array}$ & $\begin{array}{l}\text { Ada peringatan apabila ada } \\
\text { perubahan harga produk }\end{array}$ \\
$\begin{array}{l}\text { Loyalitas pelanggan } \\
\text { belum sesuai harapan }\end{array}$ & $\begin{array}{l}\text { Memberikan benefit yang } \\
\text { lebih beragam bagi } \\
\text { pelanggan loyal }\end{array}$ \\
\end{tabular}

Tabel 7. SI/TI Internal Value Chain

\begin{tabular}{ll}
\hline \multicolumn{1}{c}{ Solusi Bisnis } & \multicolumn{1}{c}{ Solusi SI } \\
\hline Ada peringatan apabila jumlah stok & SI Manajemen \\
produk berkurang hingga jumlah tertentu & Inventori \\
$\begin{array}{l}\text { Ada konfirmasi penerimaan dan } \\
\text { pengiriman produk }\end{array}$ & SI Manajemen \\
$\begin{array}{l}\text { Ada pemberitahuan apabila ada perubahan } \\
\text { harga produk }\end{array}$ & Inventori \\
$\begin{array}{l}\text { Memberikan benefit yang lebih beragam } \\
\text { bagi pelanggan loyal }\end{array}$ & Inventori \\
& SI Customer \\
& Relation \\
\hline
\end{tabular}

Tabel 8. Matrik Portfolio McFarlan Gramedia - Future Condition

\begin{tabular}{ll}
\hline Strategic & High Potential \\
\hline Data Warehouse $(*)$ & SI Online Store $(*)$ \\
Customer Relation $(*)$ & SI Self Services $(+)$ \\
SI Analisis Produk Baru(+) & \\
SI Pengembangan Usaha(+) & Support \\
\hline Key Operational & BI Publisher \\
\hline Management Inventory & SOA Unit \\
REIM & GAM Portal \\
SIM & HR Portal \\
RESA & HR Dev Application \\
POS & InfoProduct \\
RPM & \\
BO & \\
Oracle Finance & (*) Pengembangan Sistem Informasi \\
\hline Keterangan: & $(+)$ Penambahan Sistem Informasi
\end{tabular}

Dari segi organisasi SI/TI, pengelolaan SI/TI yang lebih baik diperlukan adanya unit khusus yang mengelola aplikasi SI/TI. Hal ini dirasa perlu mengingat saat ini belum ada unit yang mengelola aplikasi SI/TI, sedangkan SI/TI Gramedia akan terus berkembang mengikuti perkembangan bisnis. Keberadaan unit tersebut akan membantu pengembangan SI baru agar dapat terintegrasi dengan sistem yang telah ada.

\subsection{Analisis Kesenjangan dan Roadmap Pengembangan SI/TI}

Analisis kesenjangan organisasi dan manajemen SI/TI berdasarkan kondisi yang akan terjadi pada masa mendatang serta kondisi yang terjadi saat ini terihat pada Tabel 9.

\begin{tabular}{lll}
\multicolumn{2}{c}{ Tabel 9. Analisis Kesenjangan Organisasi dan Manajemen SI/TI } \\
\hline $\begin{array}{c}\text { Organisasi dan } \\
\text { Manajemen } \\
\text { SI/TI }\end{array}$ & Kondisi Saat ini & $\begin{array}{l}\text { Kondisi Yang } \\
\text { Akan datang }\end{array}$ \\
\hline Kompetensi & Keahlian SI/TI & SDM memiliki \\
SDM SI/TI & kurang merata & $\begin{array}{l}\text { keahlian sesuai } \\
\text { dengan }\end{array}$ \\
& & perkembangan \\
& & SI/TI \\
Penempatan & Belum ada & SDM \\
SDM dengan & pemetaan SDM & ditempatkan \\
keahlian tertentu & sesuai dengan & sesuai dengan \\
& keahlian SI & potensi dan \\
& & keahlian yang \\
& & dimiliki \\
\hline
\end{tabular}




\begin{tabular}{lll}
\hline $\begin{array}{c}\text { Organisasi dan } \\
\text { Manajemen } \\
\text { SI/TI }\end{array}$ & Kondisi Saat ini & $\begin{array}{c}\text { Kondisi Yang } \\
\text { Akan datang }\end{array}$ \\
\hline Sistem & Sebagian membeli & Mengembangkan \\
pengembangan & dari Oracle (ERP), & aplikasi yang \\
SI/TI & sebagian & meningkatkan \\
& dikembangkan & nilai tambah \\
& sendiri tetapi masih & bisnis Gramedia \\
& kurang maksimal & \\
\hline
\end{tabular}

Langkah perbaikan pada kompetensi SDM SI/TI adalah pembuatan Knowledge Management untuk alih daya pengetahuan antar karyawan dan memberikan pelatihan terhadap karyawan secara merata sesuai dengan kebutuhan perkembangan SI/TI sampai ke jenjang sertifikasi. Pemetaan karyawan SI/TI yang yang disesuaikan dengan keahlian yang dimiliki masing-masing karyawan perlu dilakukan agar SDM yang ada dapat bekerja lebih maksimal sesuai dengan keahlian masingmasing. Selain itu, perlu peningkatan kualitas SDM agar memiliki keahlian SI/TI sesuai perkembangan bisnis, serta merekrut karyawan baru yang memiliki keahlian sesuai dengan kebutuhan pengembangan SI yang dibutuhkan oleh Gramedia.

Analisis kesenjangan SI/TI didasari pada portofolio aplikasi yang ada saat ini dan dibandingkan dengan usulan portfolio untuk masa depan. Diperlukan suatu tindakan yang akan dilakukan terhadap aplikasi yang sudah diidentifikasi tersebut untuk menjawab kebutuhan sistem informasi. Tindakan yang dilakukan adalah:

- New : membuat sistem informasi yang baru

- Enhance : melakukan pengembangan sistem informasi yang sudah ada

- Retain : mempertahankan kondisi sistem saat ini

- Delete : mengeliminasi sistem yang ada saat ini

Pada saat dilakukan pengembangan sistem baru, sistem lama tetap difungsikan sampai selesainya tahapan pengembangan sistem inti dan pengguna sistem telah diberikan pelatihan yang memadai. Urutan pengembangan sistem akan didasarkan pada posisinya di kuadran portofolio aplikasi.

Dalam menyusun road map perlu dibuat skala prioritas atas aplikasi yang akan dikembangkan berdasarkan aplikasi yang lama dan pengembangan aplikasi baru. Aplikasi yang berada di kuadran key operational di urutan pertama, selanjutnya, strategic, high potential, dan terakhir support. Berdasarkan hasil analisis tersebut, dibuatlah urutan pengembangan sistem informasi seperti terlihat pada Tabel 10.

Tabel 10. Tabel Roadmap Sistem Informasi

\begin{tabular}{lllll}
\hline & \multicolumn{4}{c}{ Tahun Ke- } \\
& 1 & 2 & 3 & 4 \\
\hline SI Pencatatan Perubahan Stok & & & & \\
SI Pencatatan Transaksi Pelanggan & & & & \\
SI Program Promosi & & & & \\
SI Logistik & & & \\
SI Pemberitahuan Prosedur & & & \\
SI Kepegawaian Outsource & & & \\
\hline
\end{tabular}

\begin{tabular}{llccc} 
& \multicolumn{4}{c}{ Tahun Ke- } \\
& 1 & 2 & 3 & 4 \\
\hline SI Pencatatan Perubahan Stok & & & & \\
\hline SI Katalog Buku & & & \\
SI Management Inventory & & & \\
SI Data Warehouse & $*$ & & \\
SI Customer Relation & & $*$ & \\
SI Pengembangan Usaha & & & $*$ \\
SI Analisis Produk Baru & & & \\
SI Self Services & & & \\
SI Online Store & & & \\
\hline
\end{tabular}

Dalam implementasi strategi SI/TI perlu dilakukan program quick win yang dapat dirasakan secara langsung oleh sebagian besar pengguna. Program yang dipilih harus memiliki dampak yang besar serta memiliki resiko yang rendah. Program yang dipilih sebagai quick win yaitu: SI Customer Relation, SI Pengembangan Usaha, dan SI Analisis Produk Baru.

\section{KESIMPULAN DAN SARAN}

Penelitian ini menghasilkan kesimpulan bahwa metodologi Ward dan Peppard merupakan metodologi yang sederhana dan mudah dipahami dalam melakukan tahapan penelitian. Metode analisis value chain, CSF, PESTLE, five forces porter, matrik analisis SWOT, dan matrik portofolio McFarlan dapat digunakan untuk melakukan analisis terhadap lingkungan bisnis dan SI/TI dari Gramedia. Analisis ini menghasilkan portofolio aplikasi untuk masa mendatang serta rekomendasi roadmap implementasi SI/TI berdasarkan strategi bisnis perusahaan. Perencanaan strategis sistem informasi ini dibutuhkan komitmen dari para stakeholder untuk tetap konsisten dalam rangka mencapai visi dan misi perusahaan. Sumber daya yang dibutuhkan baik dalam hal sumber daya manusia maupun biaya juga tidak sedikit.

Berdasarkan penelitian ini, terdapat saran yang dapat digunakan oleh perusahaan ritel ataupun organisasi lain untuk pengembangan lebih lanjut:

- Penelitian selanjutnya dapat menggunakan lebih dari satu metode dalam melakukan analisis terhadap bisnis serta SI/TI pada saat ini dan masa mendatang. Hal ini memungkinkan analisis secara lebih mendalam mengetahui kondisi bisnis dan SI/TI perusahaan.

- Penelitian ini tidak membahas kebutuhan investasi, serta risiko yang dihadapi perusahaan dalam bisnis. Penelitian selanjutnya dapat mengkaji lebih mendalam terkait investasi dan risiko sehingga roadmap SI/TI yang disusun dapat memberi penjelasan secara detil kepada para stakeholder.

- Kajian terhadap perencanaan strategis sistem informasi perusahaan dapat dilakukan secara berkala untuk mengetahui sejauh mana strategi sistem informasi sudah diterapkan.

- Penelitian selanjutnya perlu mengkaji project planning dalam implementasi roadmap SI/TI 
yang sudah disusun dalam perencanaan strategis sistem informasi, yaitu mulai dari tahap penyusunan kebutuhan user terhadap sistem informasi, pengembangan, sampai implementasi SI/TI.

- Roadmap yang dihasilkan dalam penelitian ini lebih berfokus kepada sistem informasi. Penelitian selanjutnya dapat diperluas dengan rodmap dalam hal pengembangan infrastruktur dan jaringan teknologi informasi dalam bisnis ritel.

\section{DAFTAR PUSTAKA}

FADHILLAH, Y. dan WATERKAMP, J., 2016. Analisa dan Perencanaan Strategis Sistem dan Teknologi Informasi menggunakan Balance Scorecard pada Institut Bisnis Dan Informatika Kwik Kian Gie. Jurnal Sistem Informasi, Volume 12 (Issue 1), 15-29, Jakarta: Universitas Indonesia.

FORBES, 2015. Most Popular: Forbes 20 Best Foreign Retirement Havens For 2015. Retrieved from http://www.forbes.com/pictures/fgjd45eldm /1-computing-everywhere-2/

GORP KOMPAS GRAMEDIA, 2015. Document Performance Contract. Jakarta.

HADI, N.S. dan PRIHADI, L.Y., 2010. Aspek Kepemimpinan dalam Penyelarasan Strategi Bisnis - Strategi SI/TI. Yogyakarta: CIO Gajah Mada University.

HARON, H., SABRI, S. dan ZOLKARNAEN, Z. 2013. A Situtional Analys of Strategic Information System Planning in The Context of a Malaysian SME. Journal of IEEE: 3rd International Conference on Research and Innovation in Information System (ICRISS'13), 539-543.

KARDHA, F.R.D., 2011. Perencanaan Strategis Sistem Informasi pada PT. Batik Danar Hadi menggunakan Ward and Peppard Framework. Perpustakaan Universitas Gadjah Mada. Yogyakarta: Universitas Gadjah Mada.

MOLLY, B., TANAAMAH, A.R., dan SITOKDANA, M.N.N., 2017. Analisis Kinerja Sistem Informasi dan Teknologi Informasi untuk Menunjang Kinerja Karyawan menggunakan Framework IT Balanced Scorecard (Studi Kasus pada WiFi Universitas Kristen Satya Wacana). Jurnal Teknologi Informasi dan Ilmu Komputer, Volume 4 (No. 4), 318-332. Malang: Universitas Brawijaya.

O'BRIEN, J. dan MARAKAS, G., 2007. Management Information System $8^{\text {th }}$ Edition. Boston: Mc Graw Hill, Inc.

PHAM, T., PHAM D.K. \& PHAM A.T., 2013. From Business Strategy to Information
Technology Roadmap: A Practical Guide for Executives and Board Members. London: CRC Press.

PRABHU, S., 2012. Perencanaan Strategis Sistem Informasi Ritel Buku: Studi Kasus PT. Gunung Agung Tbk. Perpustakaan Universitas Indonesia, Jakarta: Universitas Indonesia.

PRANOTO, W.J. dan WIDODO, A., 2017. Strategi Penerapan Sistem Computer Based-Test (CBT) pada Seleksi Mahasiswa Baru dengan Metode Ward \& Peppard (Studi Kasus di STIKES Muhammadiyah Samarinda). Computatio: Journal of Computer Science and Information Systems, Volume 1 (No. 2), 205-216, Jakarta: Universitas Tarumanegara.

RUMIARTI, C.D. dan BUDI, I., 2016. Segmentasi Pelanggan pada Customer Relationship Management di Perusahaan Ritel: Studi Kasus PT. Gramedia Asri Media. Jurnal Sistem Informasi Volume 13 (No. 1), 1-10. Jakarta: Universitas Indonesia.

WARD, J. L. \& PEPPARD, J., 2002. Strategic Planning for Information Systems. New York: John Willey \& Sons. 
Halaman ini sengaja dikosongkan 